\title{
Retrieval is not necessary to trigger reconsolidation of object recognition memory in the perirhinal cortex
}

\author{
Marianela Santoyo-Zedillo, Carlos J. Rodriguez-Ortiz, Gianfranco Chavez-Marchetta, \\ Federico Bermudez-Rattoni, and Israela Balderas
}

División de Neurociencias, Instituto de Fisiología Celular, Universidad Nacional Autónoma de México, 04510 México D. F., Mexico

\begin{abstract}
Memory retrieval has been considered as requisite to initiate memory reconsolidation; however, some studies indicate that blocking retrieval does not prevent memory from undergoing reconsolidation. Since $N$-methyl-D-aspartate (NMDA) and $\alpha$ amino-3-hydroxy-5-methyl-4-isoxazolepropionic acid (AMPA) glutamate receptors in the perirhinal cortex have been involved in object recognition memory formation, the present study evaluated whether retrieval and reconsolidation are independent processes by manipulating these glutamate receptors. The results showed that AMPA receptor antagonist infusions in the perirhinal cortex blocked retrieval, but did not affect memory reconsolidation, although NMDA receptor antagonist infusions disrupted reconsolidation even if retrieval was blocked. Importantly, neither of these antagonists disrupted short-term memory. These data suggest that memory underwent reconsolidation even in the absence of retrieval.
\end{abstract}

Retrieval has been held as an indispensable condition to trigger memory reconsolidation (Nader et al. 2000; Dudai 2006). However, recent reports showed that inhibition of retrieval does not disrupt memory reconsolidation in several memory paradigms (Ben Mamou et al. 2006; Rodriguez-Ortiz et al. 2012; Balderas et al. 2013; Barreiro et al. 2013; Milton et al. 2013; Garcia-Delatorre et al. 2014). Some of these studies have shown that inhibition of the $\alpha$-amino-3-hydroxy-5-methyl-4-isoxazolepropionic acid (AMPA) receptors of the basolateral amygdala impairs retrieval of aversive memories, without affecting its reconsolidation (Ben Mamou et al. 2006; Rodriguez-Ortiz et al. 2012; Milton et al. 2013; GarciaDelatorre et al. 2014). Conversely, inhibition of $N$-methyl-Daspartate (NMDA) receptors disrupts reconsolidation of aversive memories but spare retrieval (Garcia-Delatorre et al. 2014).

A recent study evaluated the capacity of retrieval to trigger memory reconsolidation in a nonaversive task, i.e., the object recognition task (Balderas et al. 2013). The object recognition task is widely used to evaluate recognition memory in rodents, since it has been suggested that it maintains a close analogy to the recognition memory task used in humans to assess impairments in declarative memories (Reed and Squire 1997). In this regard, muscimol $\left(\mathrm{GABA}_{\mathrm{A}}\right.$ receptor agonist) infusions in the perirhinal cortex blocked retrieval, but this effect did not impede memory to undergo reconsolidation in a protocol of memory updating, suggesting that retrieval and reconsolidation of object recognition memory (ORM) are independent processes (Balderas et al. 2013).

It has been reported that glutamate receptor activity in the perirhinal cortex has an important and dissociative role mediating synaptic transmission in several stages of ORM. In one study, it was showed that the AMPA receptor antagonist 6-cyano-7nitroquinoxaline (CNQX) impaired ORM retrieval when infused 15 min before, since rats did not show preference for the new object. On the other hand, the group infused $15 \mathrm{~min}$ before reactivation with the NMDA receptor antagonist AP5 showed a good performance. These results suggest that AMPA but not NMDA receptors are necessary for retrieval (Winters and Bussey 2005). However, effects on ORM reconsolidation upon inhibition of AMPA and NMDA receptors remain to be tested. Therefore, the

\section{Corresponding author: balderas@ifc.unam.mx}

Article is online at http://www.learnmem.org/cgi/doi/10.1101/Im.035428.114. aim of the present study was to test whether retrieval and reconsolidation of ORM could be dissociated through AMPA and NMDA glutamate receptors activity in the perirhinal cortex. Thus, we blocked retrieval by infusing CNQX and disrupted reconsolidation by infusing AP5. To determine the specificity of these treatments on reconsolidation, we tested STM at $90 \mathrm{~min}$ and LTM at $24 \mathrm{~h}$, since treatments that disrupt reconsolidation have been shown to impair LTM without affecting STM (Nader et al. 2000).

Adult male Wistar rats from our Institute breeding colony ( $\sim 300 \mathrm{~g}$ at the beginning of the experiments) were implanted bilaterally with guide cannulae at the perirhinal cortex (PRH), posterior 3, lateral \pm 6.5 , ventral 7 (coordinates of the infusion sites from bregma $[\mathrm{mm}]$ ) (Paxinos and Watson 1998). Histological analysis revealed that animals included in the present study had the needle tips in the cerebral region of interest, PRH: -3.14 to -3.60 , with respect to Bregma (see Fig. 3A,B).

The AMPA receptor antagonist, CNQX (3 mM, TOCRIS, USA) was infused $15 \mathrm{~min}$ before the objects were presented in the reactivation phase (Winters and Bussey 2005). The NMDA antagonist receptor, 2-amino-5-phoshonovaleric acid (DL-AP5, $50 \mathrm{mM}$, TOCRIS) was infused immediately after reactivation (GuzmanRamos et al. 2010). We used physiological saline $0.9 \%$ as vehicle solution. In all cases, infusions were $1.0 \mu \mathrm{L}$ in volume over a minute and the injector was left in place for an additional minute to allow complete diffusion.

The groups tested for long-term memory (LTM) were: vehveh $(n=8)$, veh-AP5 $(n=9), \mathrm{CNQX}-\mathrm{veh}(n=10), \mathrm{CNQX}-\mathrm{AP5}$ $(n=10)$. For short-term memory (STM) the groups were: vehveh $(n=6)$, veh-AP5 $(n=6)$, CNQX-veh $(n=7)$, CNQX-AP5 $(n=6)$. All experiments were performed in independent groups.

The general protocol used for animal manipulation and the object recognition task have been described in detail elsewhere (see Balderas et al. 2012). Briefly, on the sample phase rats were allowed to explore for 5 min two identical objects (A1 and A2). The reactivation phase was performed $24 \mathrm{~h}$ later; rats were allowed to

\footnotetext{
(C) 2014 Santoyo-Zedillo et al. This article is distributed exclusively by Cold Spring Harbor Laboratory Press for the first 12 months after the full-issue publication date (see http://learnmem.cshlp.org/site/misc/terms.xhtml). After 12 months, it is available under a Creative Commons License (AttributionNonCommercial 4.0 International), as described at http://creativecommons. org/licenses/by-nc/4.0/.
} 


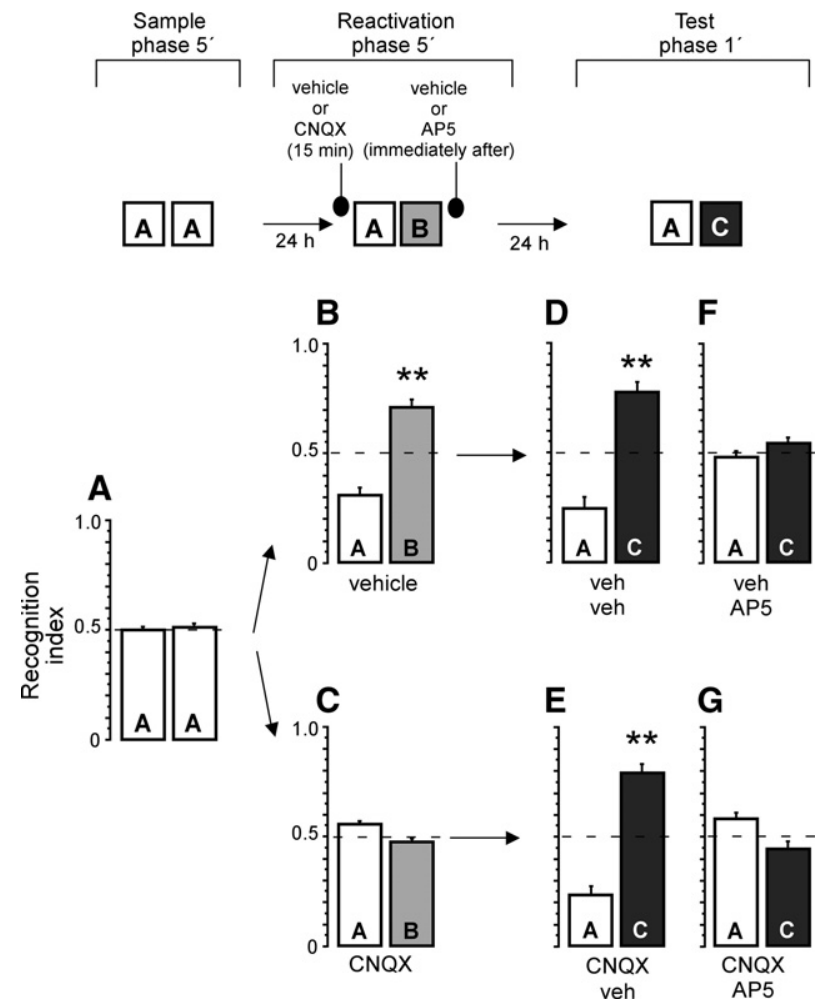

Figure 1. NMDA receptor antagonist disrupted reconsolidation of object recognition memory in the absence of retrieval. Recognition index on sample phase, when rats were exposed to two identical objects $(A)$. Animals infused with vehicle showed preference for the novel object $(B)$, contrary to rats infused in the perirhinal cortex with CNQX (C), which did not show preference for any object on the reactivation trial. $(D)$ veh/veh group showed preference for the novel object when tested. Similarly, CNQX/veh group $(E)$ showed preference for the novel object, revealing that reconsolidation was unimpaired despite retrieval inhibition. $(F, G)$ AP5 disrupted reconsolidation whether or not memory retrieval was blocked. $\left({ }^{* *}\right) P<0.01$ vs. recognition index $=0.5$.

explore one copy of the object presented in the sample phase (A3) together with a new object (B) for $5 \mathrm{~min}$. STM test was performed $90 \mathrm{~min}$ and LTM test $24 \mathrm{~h}$ after reactivation in independent groups. In all tests, the rats were allowed to explore one copy of the object presented in the sample phase (A4) together with a third new object (C) for $1 \mathrm{~min}$. Rats' behavior was recorded with a video camera mounted above the arena for subsequent analysis. All measures of exploration were made offline with the experimenter blind to treatment condition for each animal. Exploratory behavior was defined as the animal directing its nose toward the object at a distance of $<2 \mathrm{~cm}$ and/or touching it with the nose. Turning around or sitting on the objects was not considered as an exploratory behavior. Recognition indexes were calculated as follows: the time spent exploring one of the objects divided by the total exploration time. One-way analysis of variance (ANOVA) was used to determine differences between recognition indexes of novel objects on the test. Bonferroni's post hoc analyses were performed to determine differences between the two groups. Unpaired $t$-tests were performed to unveil statistical differences between CNQX and vehicle groups on recognition indexes and exploration times during the reactivation phase. One-sample $t$-tests were used to assess differences to chance level (0.5). $P$-values $<0.05$ were accepted as statistical significance. The first minute of exploration was used for statistical analysis (reactivation and test phases), since it was reported that novel objects discrimination is more evident during that period of time (Dix and Aggleton 1999; Mumby et al. 2002; Winters et al. 2011).

To test whether pharmacological inhibition of AMPA receptors disrupts retrieval of ORM we infused vehicle or CNQX 15 min before memory reactivation in the perirhinal cortex. Rats were exposed to two copies of the same object in the sample phase (Fig. 1A), one-sample $t$-test revealed no preference of any object $\left(t_{(36)}=1.00, P>0.1\right)$. Twenty-four hours later, animals were infused with either CNQX or its vehicle before memory reactivation. Control rats that received vehicle infusions displayed preference for the novel object on the reactivation session $\left(t_{(16)}=5.93, P<\right.$ 0.001) (Fig. 1B). However, CNQX infusions disrupted retrieval, since rats spent similar amount of time exploring familiar and novel objects on the reactivation session $\left(t_{(19)}=1.78, P>0.05\right)$ (Fig. $1 C)$. An unpaired $t$-test showed significant differences between vehicle and CNQX groups $\left(t_{(35)}=6.00, P<0.001\right)$. The total exploration time on the reactivation phase was similar for both groups $\left(t_{(35)}=1.66, P>0.1\right)$.

To explore whether NMDA receptors play a role in reconsolidation of ORM, CNQX and vehicle groups received a second injection of either vehicle or AP5 immediately after reactivation. On the LTM test, veh/veh and CNQX/veh groups showed preference for the novel object (Fig. 1D,E). These data indicate that CNQX effects on retrieval were transient, and that CNQX did not alter LTM or other processes such as motor skills or motivation to explore

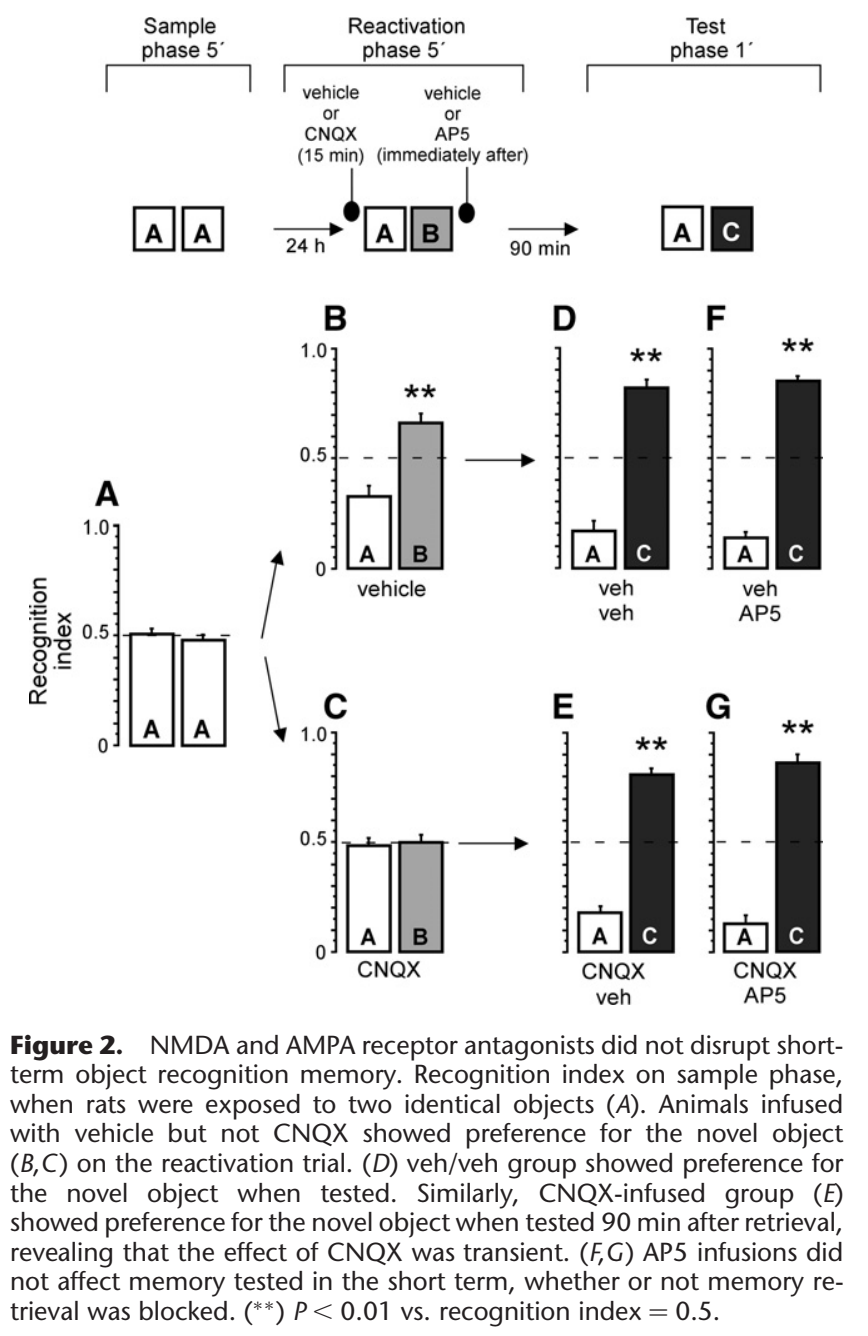


objects (one-sample $t$-tests: veh-veh $t_{(7)}=4.94, P<0.01 ;$ CNQX-veh $t_{(9)}=$ $6.40, P<0.001)$. Conversely, rats infused with both vehicle and AP5 did not display preference for the novel object on the test $\operatorname{trial}\left(t_{(8)}=0.94, P>0.1\right)$ (Fig. 1F). This result showed that reconsolidation was disrupted by AP5. Similarly, rats infused with both CNQX and AP5 were unable to discriminate familiar from novel objects on the test trial $\left(t_{(9)}=1.94, P>\right.$ 0.05) (Fig. 1G). A one-way ANOVA showed significant differences $\left(F_{(3,33)}=\right.$ 18.13, $P<0.001)$ among groups. Bonferroni's post hoc analysis indicated differences between veh-AP5 and CNQX-AP5 groups versus veh-veh and CNQX-veh groups on the test phase $\left(P^{\prime} \mathrm{s}<0.001\right)$. The present findings support that ORM reconsolidation is independent from retrieval in the perirhinal cortex, and dissociate the participation of AMPA and NMDA receptors in ORM (see Fig. 3C, bottom).

It has been widely reported that treatments that disrupt reconsolidation spare STM (Nader and Wang 2006). Therefore, on the second set of experiments we evaluated whether the effect of AP5 was specific on reconsolidation by testing the animals on the short term (90 min after the reactivation phase), and using the same pharmacological rationale as above. On the sample phase, rats were exposed to two copies of the same object (Fig. 2A), one-sample $t$-test revealed no preference for any object $\left(t_{(24)}=0.56, P>0.1\right)$. Twenty-four hours later, animals were infused with either CNQX or its vehicle before memory reactivation, and received vehicle or AP5 just after reactivation. Control rats that received vehicle infusions displayed preference for the novel object on the reactivation phase $\left(t_{(11)}=3.80, P<0.01\right)$ (Fig. $2 B)$. Rats infused with CNQX had disrupted memory retrieval as they spent similar amount of time exploring familiar and novel objects on the reactivation session $\left(t_{(12)}=0.25, P>0.1\right)$ (Figs. 2C, 3C). An unpaired $t$-test showed a significant difference between the vehicle and CNQX groups $\left(t_{(23)}=2.93, P<0.01\right)$. The total exploration time on the reactivation phase did not reveal significant differences between groups infused with CNQX and vehicle $\left(t_{(23)}=0.41, P>0.1\right)$.

On the test phase, all groups showed preference for the novel object (one-sample $t$-tests: veh-veh $t_{(5)}=8.15, P<0.001$; vehAP5 $t_{(5)}=15.68, P<0.001 ;$ CNQX-veh $t_{(6)}=11.33, P<0.001$; CNQX-AP5 $t_{(5)}=9.63, P<0.001$ ) (see Fig. 2D-G). A one-way ANOVA did not show significant differences among groups $\left(F_{(3,21)}=0.59, P>0.1\right)$. These data indicate that neither CNQX nor AP5 infusions disrupt STM.

The results presented here showed that memory reconsolidation occurring despite retrieval was blocked by CNQX and, more importantly, that AP5 disrupted reconsolidation even when behavioral retrieval was blocked. Remarkably, neither CNQX nor AP5 affect STM.
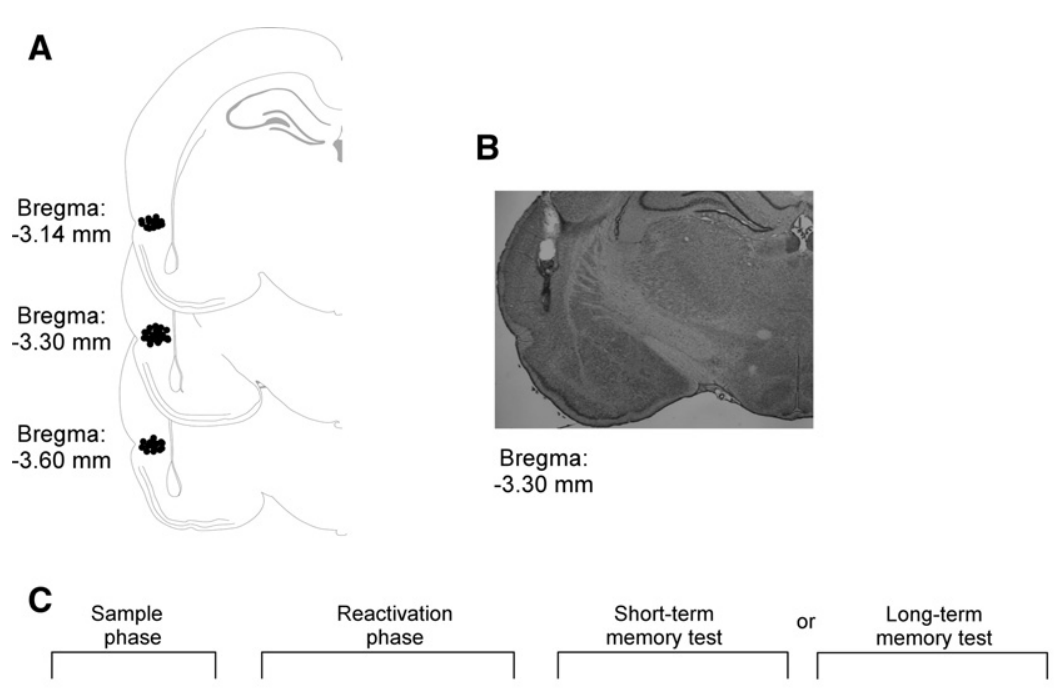

Figure 3. Schematic representation of infusion sites $(A)$ and a representative photograph $(B)$ illustrating cannula placement in the perirhinal cortex. (C) Schematic representation that summarizes the results of this study. Novel objects are depicted as a dotted-line circle since the memory trace of these stimuli are unstable; stable familiar objects memories traces are symbolized as a continued-line circle. On sample phase, new objects (" $A$ ") have an unstable memory trace; object " $A$ " becomes famil-
iar through consolidation process. On the reactivation phase, behavioral output of familiar objects is impaired by inactivation of AMPA receptors through CNQX infusion in the perirhinal cortex, then trace for familiar object " $A$ " turns unstable again since animals do not show preference for any object. However, the effect of CNQX is transient since animals showed preference for the new object (" $\left.\mathrm{C}^{\prime \prime}\right)$; these results indicated that STM or reconsolidation for object " $A$ " was not impaired by CNQX. Conversely, the inactivation of the NMDA receptors by AP5 infusions disrupts reconsolidation, even on conditions where retrieval was blocked. Importantly, STM was unaffected by AP5.

A large body of work has shown that following activation, a consolidated memory trace can return to a labile state in which it can be modified again, requiring another phase of stabilization, called reconsolidation (Nader et al. 2000; Dudai 2006). Although retrieval has been held as an indispensable condition for memory reconsolidation, several recent studies suggest that the blockade of retrieval is not enough condition to prevent reconsolidation. This conclusion is based on the observation that treatments that impair reconsolidation are effective on conditions where pharmacological inhibition of retrieval were attained, suggesting that retrieval does not trigger destabilization required for memory reconsolidation (Yasoshima et al. 2005; Ben Mamou et al. 2006; Rodriguez-Ortiz et al. 2012; Balderas et al. 2013; Barreiro et al. 2013; Milton et al. 2013; Otis et al. 2013; Garcia-Delatorre et al. 2014). Moreover, there is evidence showing that memory does not undergo reconsolidation every time it is retrieved (Vianna et al. 2001; Suzuki et al. 2004); further supporting that retrieval is not sufficient condition to trigger reconsolidation. 
Experiments in which protein synthesis was inhibited by anisomycin infusion into the perirhinal cortex showed that this region is indispensable for the occurrence of ORM reconsolidation (Winters et al. 2011). In another study, it was established that glutamate receptors in the perirhinal cortex play a role in ORM formation. By infusion of CNQX it was shown that AMPA receptors are required for encoding, STM, retrieval and consolidation; whereas AP5 receptors are necessary for consolidation but not STM or retrieval. It is worth noting that AMPA but not NMDA receptor activity within the perirhinal cortex is necessary for ORM retrieval, since CNQX but not AP5 blocked memory when applied before the test (Winters and Bussey 2005). Our findings are consistent with those reported by Winters and Bussey since we observed that CNQX was an effective treatment to disrupt retrieval of ORM. However, they found STM and LTM impairments with CNQX infusions and we did not. One possible explanation for these discrepancies is different protocols used in the two studies. While our protocol was designed to evaluate reconsolidation, Winter and Bussey's protocol was aimed to analyze consolidation. It has been shown that consolidation and reconsolidation recruit different molecular cascades (Lee et al. 2004). In addition, in the case of contextual fear conditioning both consolidation and reconsolidation rely on NMDA activity in the hippocampus. However, different downstream signaling pathways are required for the consolidation and reconsolidation processes. In this way, NMDA receptor-ERK1-BDNF has been linked to consolidation, whereas NMDA receptor IKK $\alpha$-Zif268 has been linked to reconsolidation (Lee and Hynds 2013). Nevertheless, it remains to be investigated if AMPA receptor activity leads to different signaling pathways for different stages of ORM memory formation.

Furthermore, in our study, the AMPA receptor antagonist blocked retrieval. Although it is possible that perceptual or motivational deficits were induced by the CNQX infusion, this explanation seems unlikely since we did not observe differences in the total exploration time between CNQX and its control group on the injection session. Furthermore, all groups infused with CNQX displayed high recognition indexes in the $90 \mathrm{~min}$ and 24 $\mathrm{h}$ tests, supporting that the effect of CNQX is transient. There is evidence showing that neural transmission returns to baseline 30 min after the infusion of CNQX (Bast et al. 2005), suggesting that the effects of CNQX were dissipated before memory tests were done. These results indicate that STM and reconsolidation occurred despite retrieval blockage and are congruent with a previous report showing that CNQX disrupt retrieval but do not affect STM or reconsolidation of an aversive memory task (Ben Mamou et al. 2006).

In addition, AP5 did not affect memory tested 90 min after reactivation; but interestingly, disrupted reconsolidation even when retrieval was impaired by CNQX; our results suggest that STM and retrieval mechanisms are different from those used during reconsolidation. Recently, a differential participation of AMPA and NMDA receptors was established in an aversive memory task. This study showed that blocking the AMPA receptors in the basolateral amygdala disrupted retrieval without affecting reconsolidation, while AP5 infusions impaired reconsolidation even when retrieval was blocked (Garcia-Delatorre et al. 2014).

It is well established that AMPA activity is necessary for canonical NMDA receptor activation that leads to plasticity processes. However, it has been shown that even when AMPA transmission is blocked, NMDA receptors could initiate signaling cascades that lead to nuclear gene expression by local elevation of $\mathrm{Ca}^{2+}$ probably by other mechanisms like voltage-gated $\mathrm{Ca}^{2+}$ channels (Rao and Finkbeiner 2007). Furthermore, growing evidence indicate that AMPA and NMDA receptor neurotransmission are sometimes independently involved in memory processes (Garcia-Delatorre et al. 2014).

In summary, the present work shows that pharmacological blockage of retrieval, through an AMPA receptor antagonist, does not impede the process of reconsolidation. However, inactivation of the NMDA receptors disrupted reconsolidation, even on conditions where retrieval was blocked. Importantly, neither of these antagonists disrupted STM, supporting their specific participation on retrieval and reconsolidation. These results are congruent with those that have showed that retrieval is not a requisite to undergo reconsolidation.

\section{Acknowledgments}

We thank Anali Díaz, Andrés Agoitia, and Carlos Gómez for their assistance in the experiments, and Perla Moreno-Castilla, Francisco Pérez Eugenio, and Patricia Delgado for their technical support. The research was funded by grants from Consejo Nacional de Ciencia y Tecnología (CONACYT) (155242) and DGAPA-UNAM (IN209413).

\section{References}

Balderas I, Morin JP, Rodriguez-Ortiz CJ, Bermudez-Rattoni F. 2012. Muscarinic receptors activity in the perirhinal cortex and hippocampus has differential involvement in the formation of recognition memory. Neurobiol Learn Mem 97: 418-424.

Balderas I, Rodriguez-Ortiz CJ, Bermudez-Rattoni F. 2013. Retrieval and reconsolidation of object recognition memory are independent processes in the perirhinal cortex. Neuroscience $\mathbf{2 5 3}$ 398-405

Barreiro KA, Suarez LD, Lynch VM, Molina VA, Delorenzi A. 2013. Memory expression is independent of memory labilization/reconsolidation. Neurobiol Learn Mem 106: 283-291.

Bast T, da Silva BM, Morris RG. 2005. Distinct contributions of hippocampal NMDA and AMPA receptors to encoding and retrieval of one-trial place memory. J Neurosci 25: 5845-5856.

Ben Mamou C, Gamache K, Nader K. 2006. NMDA receptors are critical for unleashing consolidated auditory fear memories. Nat Neurosci 9: $1237-1239$.

Dix SL, Aggleton JP. 1999. Extending the spontaneous preference test of recognition: evidence of object-location and object-context recognition. Behav Brain Res 99: 191-200.

Dudai Y. 2006. Reconsolidation: the advantage of being refocused. Curr Opin Neurobiol 16: 174-178.

Garcia-Delatorre P, Perez-Sanchez C, Guzman-Ramos K, Bermudez-Rattoni F. 2014. Role of glutamate receptors of central and basolateral amygdala nuclei on retrieval and reconsolidation of taste aversive memory. Neurobiol Learn Mem 111: 35-40.

Guzman-Ramos K, Osorio-Gomez D, Moreno-Castilla P, Bermudez-Rattoni F. 2010. Off-line concomitant release of dopamine and glutamate involvement in taste memory consolidation. $J$ Neurochem 114: 226-236.

Lee JL, Hynds RE. 2013. Divergent cellular pathways of hippocampal memory consolidation and reconsolidation. Hippocampus 23: $233-244$.

Lee JL, Everitt BJ, Thomas KL. 2004. Independent cellular processes for hippocampal memory consolidation and reconsolidation. Science 304: 839-843.

Milton AL, Merlo E, Ratano P, Gregory BL, Dumbreck JK, Everitt BJ. 2013. Double dissociation of the requirement for GluN2B- and GluN2A-containing NMDA receptors in the destabilization and restabilization of a reconsolidating memory. J Neurosci 33: 1109-1115.

Mumby DG, Gaskin S, Glenn MJ, Schramek TE, Lehmann H. 2002. Hippocampal damage and exploratory preferences in rats: memory for objects, places, and contexts. Learn Mem 9: 49-57.

Nader K, Wang SH. 2006. Fading in. Learn Mem 13: 530-535.

Nader K, Schafe GE, LeDoux JE. 2000. The labile nature of consolidation theory. Nat Rev Neurosci 1: 216-219.

Otis JM, Dashew KB, Mueller D. 2013. Neurobiological dissociation of retrieval and reconsolidation of cocaine-associated memory. J Neurosci 33: $1271-1281 \mathrm{a}$

Paxinos G, Watson C. 1998. The rat brain in stereotaxic coordinates, 4 th ed. Academic Press, San Diego.

Rao VR, Finkbeiner S. 2007. NMDA and AMPA receptors: old channels, new tricks. Trends Neurosci 30: 284-291. 
Reed JM, Squire LR. 1997. Impaired recognition memory in patients with lesions limited to the hippocampal formation. Behav Neurosci 111: $667-675$.

Rodriguez-Ortiz CJ, Balderas I, Garcia-DeLaTorre P, Bermudez-Rattoni F. 2012. Taste aversion memory reconsolidation is independent of its retrieval. Neurobiol Learn Mem 98: 215-219.

Suzuki A, Josselyn SA, Frankland PW, Masushige S, Silva AJ, Kida S. 2004 Memory reconsolidation and extinction have distinct temporal and biochemical signatures. J Neurosci 241: 4787-4795.

Vianna MR, Szapiro G, McGaugh JL, Medina JH, Izquierdo I. 2001. Retrieval of memory for fear-motivated training initiates extinction requiring protein synthesis in the rat hippocampus. Proc Natl Acad Sci 98: $12251-12254$
Winters BD, Bussey TJ. 2005. Glutamate receptors in perirhinal cortex mediate encoding, retrieval, and consolidation of object recognition memory. J Neurosci 25: 4243-4251.

Winters BD, Tucci MC, Jacklin DL, Reid JM, Newsome J. 2011. On the dynamic nature of the engram: evidence for circuit-level reorganization of object memory traces following reactivation. J Neurosci 31: $17719-17728$.

Yasoshima Y, Yamamoto T, Kobayashi K. 2005. Amygdala-dependent mechanisms underlying memory retrieval of conditioned taste aversion. Chem Senses 30 Suppl 1: i158-i159.

Received April 13, 2014; accepted in revised form July 11, 2014. 


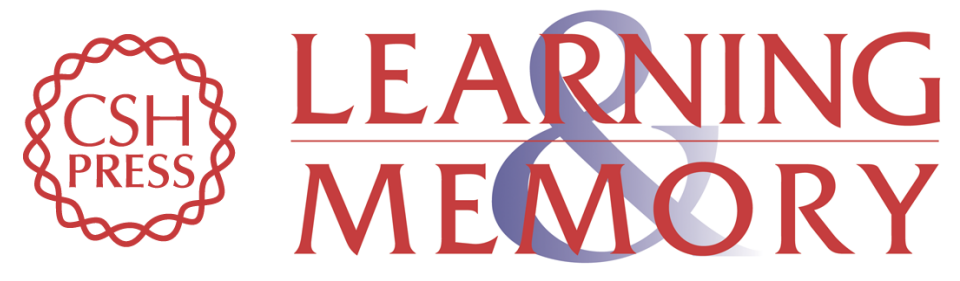

\section{Retrieval is not necessary to trigger reconsolidation of object recognition memory in the perirhinal cortex}

Marianela Santoyo-Zedillo, Carlos J. Rodriguez-Ortiz, Gianfranco Chavez-Marchetta, et al.

Learn. Mem. 2014, 21:

Access the most recent version at doi:10.1101/lm.035428.114

\begin{aligned} & \hline References $\begin{array}{l}\text { This article cites } 24 \text { articles, } 9 \text { of which can be accessed free at: } \\ \text { http://learnmem.cshlp.org/content/21/9/452.full.html\#ref-list-1 }\end{array} \\ & \begin{aligned} \text { Creative } \\ \text { Commons } \\ \text { License }\end{aligned} \begin{array}{l}\text { This article is distributed exclusively by Cold Spring Harbor Laboratory Press for the } \\ \text { first } 12 \text { months after the full-issue publication date (see } \\ \text { http://learnmem.cshlp.org/site/misc/terms.xhtml). After } 12 \text { months, it is available under } \\ \text { a Creative Commons License (Attribution-NonCommercial } 4.0 \text { International), as } \\ \text { described at http://creativecommons.org/licenses/by-nc/4.0/. }\end{array} \\ & \begin{array}{c}\text { Receive free email alerts when new articles cite this article - sign up in the box at the } \\ \text { top right corner of the article or click here. }\end{array} \\ & \begin{array}{c}\text { Service } \\ \text { terting }\end{array}\end{aligned}$ 